1.1311）以及磷灰石高度贫 REE 为特征. 因此，应 用佛罪岩中磷灰石的 $\mathrm{Sr}$ 同位素和 $\mathrm{Rb} 、 \mathrm{Sr}$ 、 REE 等特 征来研究其成因、演化与矿化作用是有利的. 此外, 还可根据不同形成机理的伟晶岩之 $\left({ }^{87} \mathrm{Sr} /{ }^{86} \mathrm{Sr}\right)$ ap
比值与各种矿化类型的关系作为找矿评价标志.

伍勤生 刘青莲

（中国有色金属工业总公司矿产地质研究院，桂林）

\title{
华北棉区防治棉铃虫的新策略在 十万亩面积上应用成功*
}

华北棉区防治棉铃虫 (Heliothis armigera (Hübner））的传统策略是重点防治第二代、力保伏前桃， 经济间值定为百株棉花 15 粒卵或 5 头幼虫. 随着 生产条件的变化, 这一策略遇到了一些严重的经济 生态学问题. 为此, 中国科学院动物研究所运用系 统分析和经济生态学理论, 自 1980 年至 1985 年在 河北省饶阳县和安徽省滩溪县及涡阳县进行了一系 列试验研究, 提出在产量水平中等以上的棉田, 把 第二代经济阈值提高约 10 倍,并辅以合理的人工摘 蕾. 在 1983 年和 1984 年验证结果的基础上, 1985 年饶阳县全面推广这一新的技术策略, 实际应用面 积 10 万亩. 1985 年第二代棉输虫大发生, 百株累 计卵量为 557 粒, 仅施药一次, 容许幼虫为害一部分 蕾. 随后通过人工摘蕾, 使每株棉花总损失蕾数(包
括被害蕾)达到 4 个. 这样,节省用药 50\% 以上. 若 按 $2.5 \%$ 㴪氧菊酷 (Decamethrin) 乳剂计，全县节 省的农药为 2 吨左右. 此外, 每亩节约喷药用工半 个. 全县节约的农药及用工费估计为 17 万元.

今年棉花出苗比常年晚 10 天左右, 7、8 月降雨 $625.5 \mathrm{~mm}$ ，为常年均值的 $186 \%$ ，这些条件对棉花的 补偿不利。尽管如此，采用新的防治策略后仍显著 增产。通过比较 7 块地的处理区和对照区的实收籽 棉产量, 新策略平均增产 $21.39 \%$,合每亩籽桶 75.6 斤或 37.80 元. 这样,全县共获得经济净收益 395.0 万元.

\section{盛承发 李树清* 吴国伟 (中国科学院动物研究所,北京; *河北省绕阳县五公病虫测报站）}

\section{人淋巴细胞表面与羊红细胞结合的蛋白质*}

80 年代初作者等报道了人 $\mathrm{SRBC}$ 受体的分离提 纯及性质研究. 最近按 Mendes 法, 即以 SRBC 吸附 人淋巴细胞 $45^{\circ} \mathrm{C}$ 保温上清 (SHPL) 中的结合蛋白 质 $(\mathrm{BP})$, 免度自体羊. 按理, 在人淋巴细胞表面 与SRBC 结合的蛋白质即为 $\mathrm{SRBC}$ 受体. 但在分析了 SRBC 或其血影吸收 SHPL 后洗脱液中蛋白质的 PAGE 图谱, 却出现多条区带. 比较 SHPL 在 SRBC 吸收前后的数胶过滤图谱, 被吸附的蛋白质亦不限 于在一个峰上. 以此吸附蛋白质的 SRBC 免等自体 羊得抗 SRBC-Bp 抗血清, 提纯 IgO, 与 Sepharose4B 做成免度吸附柱, 用其分离人淋巴细胞和人 $\mathrm{T}$ 细胞 株 HPB-ALL 细胞 SHPL 或人血清中 Bp. 经 PAGE 和 SDS-PAGE (还原) 比较三者洗脱组分相符, 其主 要区带 $M W$ 均在 I. $60,000-70,000$, II. 52,00059,000 及 III. $20,000-26,000$. 而 I 组与 II 组虽经

\footnotetext{
*中国科学院科学基金资助的课题.
}

高效液相 (HPLC) 亦难分离. 经 HPLC 纯化的 Bp 与 OKT11 反应阳性. 本文报道人淋巴细胞表面不止一 种蛋白质能与 SRBC 结合, 是前人所未注意到的.

文献报道多种抗人 SRBC 受体的单克隆抗体 (McAb) 所沉腚的蛋白质, 不论还原或不还原, $M W$ 均为 40,000-50,000 的一条钝链. 最近英国 Brown 获得一组 MW 在 50,000-58,000 间具有微不均一 性的糖蛋白, 即为 $\mathrm{SRBC}$ 受体 (现称 $\mathrm{CD}_{2}$ 抗原). 据此, 我们设想在本实验中多种 $\mathrm{Bp}$ 样品的 50,000 组分与 60,000 组分难以分离的现象很可能为一假象. 为此, 对 SRBC-BP 进行了在还原与不还原条件下的 SDSPAGE. 由于一般进行 SDS-PAGE 时样品处理(不论 还原或不还原)均需在沸水浴中加热 $5 \mathrm{~min}$ ，为避免 加热时对不还原 $\mathrm{Bp}$ 的影响，我们设计了一组不加热 亦不还原的处理样品方法 (称平衡法). 即将样品置 在含 $5 \% \mathrm{SDS}$ 的 $50 \mathrm{mmol} / 1$ Tris-acetate 缓冲液. $\mathrm{pH}$ 7.8 平衡过夜. 周批样品经三种处理在同一凝胶板 上做 SDS-PAGE. 三次实验结果如下表: 


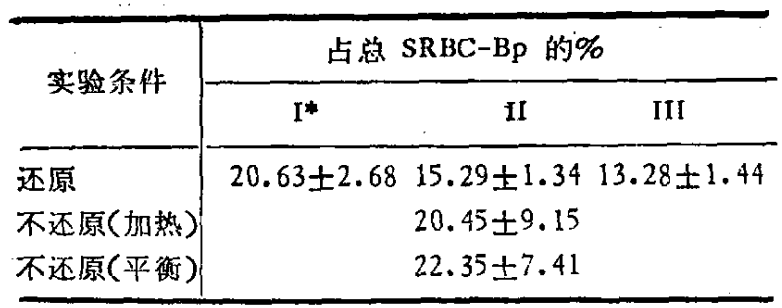

* MW:I 组 60-70 KD, II 组 52-59 KD, III 组 $20-26 \mathrm{KD}$.

概括如下：1）仅还原样品有三条主要蛋白区带，两 种不还原样品主要蛋白质为 II 组, 即 $52,000-$ 59,$000 ; 2$ ) 在高分子部分, 还原样品在 200,000 , 82,000 有较浅区带, 而不还原 (平衡组) 在 205,000 上下及 $<116,000$ 有较深区带, 不还原 (加热组)
则较复杂. 提示在不还原条件下，人淋巴细胞表 面除有 52,000一 59,000 结合蛋白质外, 尚有在 $\sim 200,000$ 的多种蛋白质. 还原后, 高 MW 的蛋白 量减少 (染色浅), 而出现 I 组及 III 组蛋白质, 它 们可能均为高分子蛋白质在还原条件下出现的亚单 位. 本文强调了在人淋巴细胞表面的 SRBC-Bp 可 能学有高分子部分, 至于其是否有 SRBC 受体 功能 的研究, 尚在进行中.

吴蔚 刘亚霞 宋晓国 曾 真 (军事医学科学院基础医学研究所, 北京)

李亚萍

(北京军区 263 医院化验科)

\section{中国物理学会设立“吴传雄物理奖”评委会}

为纪念吴健雄教授对科学作出的重大贡献，为奖励我国青年物理学工作者的学术成就，加 速物理学的发展，促进社会主义现代化建设，香港亿利达工业发展集团有限公司在我国设立 “吴健雄物理奖”。中国物理学会受该公司的委托,设立“吴健雄物理奖”评选委员会,负责初审 后请奖项目的评定工作。该奖将授予我国青年物理学工作者主要在国内物理学研究中发现新 现象，阐明规律，运用规律解决关键问题等方面取得优秀实验物理各学科研究成果的个人或集 体。获奖者将颁发奖金、荣誉证书并授予金质奖章。该奖每年评选一次，每年九月三十日前将 请奖项目报北京六 $\bigcirc 三$ 三信箱中国物理学会。一九八六年度请奖项目从即日起开始申报。

[ 程义慧] 